\title{
Contribuições da neuropsicologia para a psicologia clínica e a educação
}

\author{
Lúcia Helena Tiosso Moretti e João Batista Martins \\ Universidade Estadual de Londrina
}

\begin{abstract}
Resumo
O objetivo foi estudar alguns aspectos da avaliação neuropsicológica e testes tradicionais aplicados individualmente a 12 sujeitos (8 a 13 anos). A análise qualitativa mostrou aspectos problemáticos na avaliação tradicional.

Palavras-chave: avaliação neurológica, testes e medidas.
\end{abstract}

\section{Contributions of the neuropsychology to clinical psychology and education}

\section{Summary}

The aim was to study somme aspects ofneuropsychological evoluation and traditional tests aplyed individualy to 12 subjects ( 8 to 13 years old). The qualitative analyses showed problematic aspects in the traditional evaluation.

Key words: Neuropsychological evaluation, tests and measurement.

O objetivo deste trabalho é fazer algumas considerações acerca das possíveis contribuições da neur9psicologia para a psicologia clínica e educação. Consideramos a neuropsicologia como a ciência que tem por objeto o estudo das relações entre as funções do sistema nervoso e o comportamento humano (Luria, 1966). Através dela podemos compreender os processos mnemônicos, perceptivos, de aprendizado e de solução de problemas, dentre outras atividades cognitivas.

O interesse pelo estudo dos mecanismos da atividade cerebral nos levou a buscar subsídios nas obras de um respeitado clássico da literatura neuropsicológica - Alexandr Romanovich Luria (1902-1977). Segundo ele, a investigação neuropsicológica permite conhecer a estrutura interna dos processos psicológicos e da conexão interna que os une. Ela também nos possibilita realizar um exame pormenorizado das alterações que surgem nos casos de lesões cerebrais locais, assim como as maneiras pelas quais os processos psicológicos são alterados por essas lesões (Luria, 1966).

A contribuição deste exame também é extensiva ao processo ensino-aprendizagem em geral, pois nos permite estabelecer algumas relações entre as funções psicológicas superiores - linguagem, atenção, memória etc. - e a aprendizagem simbólica (conceitos, escrita, leitura etc.), ou seja, o modelo neuropsicológico das dificuldades da aprendizagem preocupa-se em reunir uma amostra de funções mentais superiores envolvidas na aprendizagem simbólica as quais estão, obviamente, correlacionadas com a organização funcional do cérebro. Sem essa condição sine qua non, a aprendizagem não se processa normalmente e, neste caso, podemos nos deparar com uma disfunção ou lesão cerebral.

As disfunções cerebrais, bem como as lesões, interferem no processamento da informação que o aprendizado envolve: 1. de recepção (ocasiona problemas perceptuais), 2. de integração (surgem dificuldades na retenção - memória e elaboração) e 3. na expressão (surgirão distúrbios na ordenação, seqüencialização, planificação e execução (Johnson e Myklebust, 1983).

Luria (1973) estabelece as relações entre as funções psicológicas e o funcionamento cerebral 
considerando o cérebro como um sistema interrelacionado a partir de três unidades funcionais: I) unidade para regular o tono, a vigília e os estados mentais (área de projeção que abrange a formação reticular), 2) unidade para receber, analisar e armazenar informações (área de projeção que abrange parietal, occipital e temporal primários; área de associação que abrange parietal, occipital e temporal secundários; 3) unidade para programar, regular e verificar a atividade (área de sobreposição que abrange as áreas pré-frontais e frontais). As áreas de projeção estão relacionadas com a sensibilidade, a motricidade, e as áreas de associação e de sobreposição estão relacionadas com funções psíquicas complexas: gnosias, linguagem, esquema corporal, memória, emoções etc. (Machado, 1981).

Podemos definir a exploração neuropsicológica na infância em dois grandes grupos: 1 . a investigação mais rigidamente conduzida sob a forma de uma bateria sistematizada, levando-se em conta, na inclusão de cada item, os mecanismos subjacentes à função examinada; 2. o exame menos sistemático decorrente da re-leitura neuropsicológica do próprio psicodiagnóstico clássico e de toda produção escolar dos dados da anamnese, bem como da observação do comportamento.

Ao fornecer subsídios para investigar a compreensão do funcionamento intelectual da criança, em nosso caso, a neuropsicologia pode instrumentar diferentes profissionais, tais como médicos, psicólogos, fonoaudiólogos, psicopedagogos etc.; promovendo uma intervenção terapêutica mais eficiente.

No que se refere aos problemas de aprendizagem, Tiosso $(1989,1993)$ tem assinalado que reprovações escolares têm múltipla etiologia, justificando, portanto, múltiplo enfoque. Neste processo ensino-aprendizagem, consideramos que a avaliação global das funções psicológicas deve levar em conta todo o mecanismo cerebral, nos seus níveis sucessivos de evolução. Sendo assim a avaliação neuropsicológica é a única forma possível de se avaliar uma determinada função, posto que somente quando a mesma é colocada à prova (mediante testes específicos), podemos observar sua integridade ou comprometimento (Lefevre, 1983; Mackinnon e Yudofsky, 1988; Matos, 1992).

Uma referência para a organização da bateria neuropsicológica, tanto para crianças como para adultos, são as próprias provas que compõem a avaliação psicológica tradicionalo psicodiagnóstico. Quase todas as baterias de exploração neuropsicológica de crianças e adultos incluem testes do psicodiagnóstico clássico. Estas no geral são usadas em parte pela necessidade de não sobrecarregar a avaliação que é em si longa.

Bem utilizados, portanto, os testes tradicionais, tais como o WISC - Escala Wechsler de Inteligência para Crianças, Teste Guestáltico Visomotor de Bender, Raven - Matrizes Progressivas, CA T - Teste de Apercepção Temática para Crianças, Teste de Apercepção Temática - TAT (para pessoas acima de 10 anos e adultos), ou outras modalidades de desenho infantil; podem, quando analisados sob o prisma neuropsicológico, trazer grande contribuição sobre o funcionamento cerebral.

Assim, objetivamos com essa pesquisa estabelecer as correlações entre alguns itens da avaliação neuropsicológica inspirada em Luria (Christensen, 1975) e alguns testes tradicionais utilizados no psicodiagnóstico, o que nos permitirá avaliar a sua eficácia e aplicabilidade no que diz respeito aos distúrbios de aprendizagem e conduta. Além disso, com o presente estudo, pretendemos analisar, através da avaliação neuropsicológica, crianças com distúrbios no processo ensinoaprendizagem, sobretudo as que apresentarem dificuldades na esfera afetivo-emocional. 


\section{Método}

\section{Sujeitos}

Participaram desta pesquisa 12 crianças com idades entre 8 e 13 anos, estudantes nas séries iniciais do primeiro grau, que foram encaminhadas para a clínica psicológica da UEL com a queixa de dificuldades de aprendizagem e problemas de conduta.

\section{Material}

Para o psicodiagnóstico foram utilizados os seguintes instrumentos:

1. Anamnese com os pais da criança; 2. Entrevista com a criança; 3. Exame Neuropsicológico (Chirstensen, 1975): onde foram avaliadas as funções motoras, organização acústico/motora, função sensitiva, função visual, fala receptiva, fala expressiva, escrita/leitura, aritmética, memória, processos lógicos; 4. Redação com tema livre; 5. Teste Guestáltico VisoMotor de Lauretta Bender (Clawson, 1980); 6. Teste de Imitação de Gestos de Berges/Lezine (Berges \& Lezine, 1987), 7. Teste Desenho Estória (Trinca, 1986).

As provas selecionadas para avaliação neuropsicológica são compostas de itens verbais e não-verbais, adequadas às faixas etárias das crianças do estudo.

\section{Procedimento}

As aplicações dos testes foram individuais, com 50 minutos de duração cada sessão. Os exames foram realizados junto à Clínica Psicológica do Centro de Ciências Biológicas da Universidade Estadual de Londrina, em duas salas de Ludoterapia, as quais são específicas ao desenvolvimento do estudo. As provas foram aplicadas e avaliadas por acadêmicos, sob nossa supervisão.

\section{Resultados e discussão}

A análise qualitativa dos testes (Teste Guestáltico Viso-Motor e Teste Desenho Estória); da redação (no que diz respeito ao seu conteúdo); complementados pela anamnese e entrevista com as crianças, nos indicam que as crianças têm um nível elevado de angústias e ansiedades frente ao aprender; baixa frustração, utilizam muitas defesas, uma dinâmica de relacionamento interpessoal e familiar bastante conflitiva, o que se expressa através de sentimentos de ambivalência; conflitos em relação às ações e conteúdos bons e maus e sentimentos cindidos.

Quanto aos resultados na Prova de Imitação de Gestos, os escolares não apresentaram dificuldades na resolução dos itens requeridos.

A avaliação neuropsicológica revelou que as crianças não apresentaram comprometimentos oriundos de lesão cerebral. Nos itens diretamente relacionados com a escrita/leitura e raciocínio lógico matemático, as crianças apresentaram dificuldades na realização de sínteses nas relações entre partes e todo: ou elas consideravam o todo em detrimento das partes, ou vice-versa.

Estes dados nos possibilitam estabelecer uma relação entre o teste neuropsicológico com os dados obtidos nos testes anteriores. Como foi assinalado, as crianças apresentaram uma dinâmica de personalidade carregada de intensos conflitos, ambivalências etc..., o que pode estar subjacente à dificuldade de elaboração de sínteses no plano cognitivo (apontado pela avaliação neuropsicológica), caracterizando, portanto, o processo inibitório na aprendizagem. 
Os resultados nos levam para uma questão sempre presente nas discussões acerca das crianças com dificuldades de aprendizagem, qual seja, o papel da afetividade e das emoções na determinação desse tipo de dificuldade. Geralmente, as crianças "que vão mal na escola" são avaliadas exclusivamente em função de seus processo cognitivos. A pesquisa ora realizada nos sugere que os aspectos afetivos e emocionais devem ser considerados tanto na avaliação como no encaminhamento destas crianças. Ou seja, nosso "olhar" deve convergir todos os aspectos envolvidos nos processos de aprendizagem.

O conjunto dos instrumentos utilizados nos possibilita uma avaliação global das capacidades da criança, bem como das dificuldades encontradas por ela, quanto ao seu desempenho no dia a dia. Não se trata de "rotular" ou "enquadrar" a criança como integrante de grupos problemáticos e sim evitar que tais dificuldades possam impedir o desenvolvimento salutar da criança.

No que diz respeito ao avaliação neuropsicológica, este instrumento nos permite elaborar e organizar, de forma concreta, os dados diagnósticos, os quais, junto aos demais instrumentos empregados na avaliação, auxilia a elaboração de um diagnóstico mais completo.

\section{Referências}

Berges, J. \& Lezine, I. (1987). Teste de Imitação de Gestos. Porto Alegre:Artes Médicas. (cl978). Tradução do francês de Cleonice Paes Barreto Mourão e Consuelo Fortes.

Christensen, A. (1975). Luria's Neuropsychological Investigation Text andManual. New Y ork:Spectrum.

Clawson, A. (1980). Bender Infantil. Porto Alegre:Artes Médicas. (cl978). Tradução do inglês de Jurema Alcides Cunha.

Johnson, D. \& Myklebust, H. R. (1983). Distúrbios de Aprendizagem. S. Paulo:Pioneira. Tradução do inglês de Maria Zanella Sanvicentes.

Koppitz, E. M. (1984). EI Test Guestático Visomotor Para Niños. Buenos Aires:Guadalupe.

Lerevre, B. H. (1983). Adaptação da Investigação Neuropsicológica de Luria. Neurobiologia. 46 (2):141-170.

Luria, A. R. (1966). Higher Cortical Functions in Man. New York:Basic Books.

Luria, A. R. (1973). The Working Brain. An Introduction to Neuropsychology. New York:Basic Books.

Machado, A. (1981). Neuroanatomia Funcional. São Paulo:Atheneu.

Mackinnon, R. A. \& Yudofsky, S. C. (1988). Avaliação Psiquiátrica. Porto Alegre:Artes Médicas. (cI986). Tradução do inglês de Maria Cristina Goularte.

Matos, P. (1992). Curso de Neuropsicologia. Jornal Bras. Psiquiatria. 41 (8):375-378.

Tiosso, L. H. (1993). Contributo Dalla Neuropsicologia Alia Psicologia Clínica e All’Educazione. Roma. Pesquisa do Programa do Pós- Doutorado. Università Degli Studi di Roma "La Sapienza".

Tiosso, L. H. (1989). Dificuldades Na Aprendizagem da Leitura e Escrita: Uma Visão Multidisciplinar. São Paulo. Tese de Doutorado. Instituto de Psicologia da USP.

Trinca, W. (1986). Procedimento Desenho-Estória. S.Paulo:EPU.

Zazzo, R. (1968). Manual para Exame Psicológico da Criança. S. Paulo:Mestre Jou. (cl960). Tradução do francês por Luis Darós. 